\title{
ELECCIONES AUTONÓMICAS GALLEGAS 2001: CRÓNICA DE UN RESULTADO ANUNCIADO
}

ÁLVARO XOSÉ LÓPEZ MIRA

Profesor titular de Ciencia Política

y de la Administración

Universidad de Vigo 


\section{SUMARIO}

1. Antecedentes. Principales causas de una mayoria absoluta. 2. ResulTADOS. 3. ANÁlISIS DE LOS RESULtAdOS. 


\title{
ELECCIONES AUTONÓMICAS GALLEGAS 2001: CRÓNICA DE UN RESULTADO ANUNCIADO
}

POR

\author{
ÁLVARO XOSÉ LÓPEZ MIRA \\ Profesor Titular de Ciencia Política y de la Administración \\ Universidad de Vigo
}

1. ANTECEDENTES. PRINCIPALES CAUSAS DE UNA MAYORÍA ABSOLUTA

La cuarta mayoría absoluta del actual Presidente autonómico gallego, su avanzada edad y el hecho de haber tenido un cierto protagonismo político en el tardofranquismo, compatibilizado con su conversión democrática y, más recientemente, su fervor autonomista, son circunstancias que pueden mover a perplejidad al observador externo de la escena política de Galicia. Si todo ello lo especiamos con unos cuantos estereotipos -el conservadurismo intrínseco de los gallegos; su feroz individualismo; el proverbial atraso económico que padecen; el clientelismo político extremo, etc.-, se puede obtener la sensación o el convencimiento de que Galicia es extraña más que diferente, está alejada de la realidad moderna del resto de España y de Europa y se halla ubicada en un estadio político-social pre-democrático e inamovible.

No dedicaremos demasiado tiempo a desmontar este circunstancial conjunto de tópicos. Manuel Fraga, simplemente, se ha incorporado a una nómina de Presidentes autonómicos que consiguen ver 
prolongados sus mandatos con aparente facilidad: Andalucía, Extremadura, Castilla-La Mancha, por no hablar de Cataluña, son muestra representativa de que las inferencias deben orientarse por senderos más racionales y científicos; quizás sea nuestro modelo regional el que propicie dichos resultados 1 . En segundo lugar, el tiempo biológico del ser humano no parece haber hecho demasiada mella en un candidato próximo a los 80 años que, simultáneamente, forzó una renovación del resto de su lista electoral bastante más profunda que la de los otros contendientes en liza (las listas del Bloque Nacionalista Galego eran un calco de las de cuatro años antes). Por fin, no parece necesario recordar la cantidad de cuadros partidarios que surgieron de la cantera política del anterior régimen; bastantes de ellos continúan en activo, sólo que de forma menos estentórea que Manuel Fraga.

Pero, sin duda, este apresurado comentario no debe excluir dos elementos que nos parecen determinantes para explicar lo acontecido en los últimos comicios gallegos, al menos tanto como la propia fortaleza del Partido Popular en esta Comunidad 2. El primero de ellos estriba en el hecho de que los dos partidos que forman la oposición parlamentaria (PSOE y BNG) están, normalmente, sobre todo el primero de ellos, más preocupados por restarle votos al otro que por ganar mayoritariamente las elecciones; el patético espectáculo que están ofreciendo tras haber empatado a escaños para ocupar pequeñas cuotas institucionales (Vicepresidencia segunda del Parlamento, escaño de senador autonómico), son una muestra de que son más los factores separadores que los unificadores (a pesar de haber pactado numerosos gobiernos municipales en 1999).

El Partido Socialista ha presentado cinco candidatos diferentes en las seis elecciones autonómicas celebradas hasta la fecha; las múltiples divisiones internas del partido se manifiestan cada poco y una de ellas es determinante para inviabilizar el acuerdo para un Gobierno

1 Sin entrar en profundos análisis, parece claro que en las cuatro Comunidades Autónomas (País Vasco, Cataluña, Galicia, Andalucía) que tienen sus propios ciclos electorales se sigue imponiendo, con pequeños matices, la fuerza política que triunfó en los respectivos primeros comicios autonómicos. Carentes de un modelo de federalismo fiscal que responsabilizase a los gestores autonómicos en la partida de gastos y contando con medios de comunicación públicos más o menos instrumentalizados, se puede establecer una cierta correlación, aunque sea parcial, con la línea de continuidad gubernamental no exclusiva de Galicia.

2 Convendría no olvidar que en las elecciones de 1989, primeras a las que se presentó Manuel Fraga, éste obtuvo únicamente 33 escaños, precisando el apoyo del Partido Centristas de Galicia y sus cinco diputados para conseguir mayoría absoluta ajustada (por escaños, ya que no por votos) en el Parlamento autonómico. 
autonómico compartido con el BNG: la corriente encabezada por el carismático Alcalde de A Coruña, Francisco Vázquez, quien conjunta las alabanzas a la actual Xunta de Galicia con las críticas a su propio partido y vilipendiosas iracundias contra los nacionalistas gallegos ${ }^{3}$. Ya no parece fruto de la casualidad la circunstancia de que, sistemáticamente, el Partido Popular gane todas las elecciones en dicha urbe, con la única excepción de las locales (en las últimas este partido presentó como candidato a un político neófito originario de Vigo, impidiendo que lo fuese Augusto César Lendoiro, entonces Presidente de la Diputación y líder de la oposición municipal).

Por su parte, el Bloque Nacionalista Galego, que consiguió el milagro de unificar políticamente a la mayoría del antes disperso espectro nacionalista, se ha mostrado incapaz de sacudirse el estigma de radicalismo para convencer a sectores moderados del electorado gallego que se sienten más cómodos con el tibio y abúlico galleguismo que, en ocasiones, emanan -cada vez menos- algunos círculos del Partido Popular de Galicia. La captación del voto joven en un país con una pirámide de población envejecida, no resulta suficiente para atraer un electorado de centro al que le resulta demasiado exigente el doble posicionamiento político que demanda el Bloque: izquierdismo y nacionalismo de forma simultánea y con dosis variables. Por otro lado, el sesgo intelectual de buena parte de su cúpula dirigente, con especial relevancia en su líder, Xosé Manuel Beiras, parece excesivo para importantes segmentos de la sociedad, máxime en los tiempos de simplificación de mensajes políticos en los que nos encontramos inmersos.

El segundo de los elementos que señalábamos como determinantes lo supone la inexistencia de algún medio de comunicación social con cierta relevancia $-y$ no nos referimos a los medios públicos, en especial la Televisión de Galicia, que constituyen un burdo insulto a la inteligencia 4- que ejerza de voz crítica y contrapoder al político que ocupa de forma abrumadora (Xunta, Diputaciones y la mayoría de los municipios)

3 En plena campaña, el teniente de alcalde coruñés y número 1 en la lista de esa provincia, Méndez Romeu, declaró públicamente que rompería la disciplina de voto de su partido si éste decidiese apoyar a Xosé Manuel Beiras como candidato a la Presidencia de la Xunta.

4 El Centro Territorial en Galicia de RTVE está esforzándose por superar a su homóloga autonómica. La emisión de un lanzamiento de huevos a la pechera del Presidente en funciones la noche de apertura de campaña, provocó la separación automática de la misma del veterano realizador responsable de tal "desvio informativo". 
el Partido Popular. El disperso entramado oficial que permite subvencionar a unos medios que, posiblemente, disueltos en la competitividad del mercado desaparecerían en su casi totalidad, difícilmente controlable por la oposición parlamentaria por mucho que suponga un secreto a voces, imposibilita la mínima formación de una conciencia social crítica o el desarrollo del periodismo de investigación en aspectos molestos para la red gubernamental. El tema ha sido estudiado y demostrado científicamente en sede académica ${ }^{5}$, pero ello no impide que la figura del actual Presidente de la Xunta resulte intocable, por más que en bastantes ocasiones fuese merecedor de algún reproche por sus no pocos desatinos. Antes al contrario, de creer las versiones, casi monolíticas, de los medios gallegos, todas las excelencias que cabe encontrar a lo largo y ancho del ecúmene gallego, sean del pasado, del presente o futuros, se deben a una sola persona: Manuel Fraga.

\section{RESULTADOS}

\begin{tabular}{|c|c|c|c|c|c|c|c|c|c|}
\hline \multirow[t]{2}{*}{$\overline{\text { GALICIA }}$} & \multicolumn{3}{|c|}{ Sin voto emigrante } & \multicolumn{3}{|c|}{ Voto emigrante } & \multicolumn{3}{|c|}{ Con voto emigrante } \\
\hline & Votos & $\%$ & Escaños & Votos & $\%$ & Escaños & Votos & $\%$ & Escaños \\
\hline Censo & 2.298 .857 & & & 268.435 & & & 2.567 .292 & & \\
\hline Votantes & 1.440 .219 & $64^{\prime 2}$ & & 67.883 & $25 ’ 3$ & & 1.543 .954 & $588^{\prime} 8$ & \\
\hline Abstención & 823.211 & $35 ' 8$ & & 200.552 & 747 & & 1.023 .763 & $41 ' 2$ & \\
\hline $\mathrm{PP}$ & 745.944 & 50 '9 & 41 & 45.964 & 677 & & 791.908 & $51^{\prime} 2$ & 41 \\
\hline BNG & 341.751 & $233^{\prime} 3$ & 17 & 4.223 & 62 & & 345.974 & 224 & 17 \\
\hline PSOE & 320.283 & $21 ' 8$ & 17 & 14.184 & $20 \% 8$ & & 334.467 & $21^{\prime} 6$ & 17 \\
\hline Otros & 32.241 & $2^{\prime} 1$ & & 3.311 & & & 35.552 & 23 & \\
\hline $\begin{array}{l}\text { Votos } \\
\text { nulos }\end{array}$ & 10.088 & 07 & & & & & 10.762 & 07 & \\
\hline $\begin{array}{c}\text { Votos en } \\
\text { blanco }\end{array}$ & 25.764 & 18 & & & & & 25.988 & 17 & \\
\hline
\end{tabular}

5 Recientemente, el profesor de la Facultad de Periodismo de Santiago de Compostela, Luís Álvarez Pousa, ha señalado la cifra de treinta mil millones de pesetas entregados a fondo perdido (publicidad excluida) desde 1989 a las empresas de comunicación gallegas por parte de los distintos organismos del Gobierno autonómico. 


\begin{tabular}{|c|c|c|c|c|c|c|c|c|c|c|c|c|c|}
\hline \multicolumn{2}{|c|}{ PROVINCIAS } & \multicolumn{3}{|c|}{ A Coruña } & \multicolumn{3}{|c|}{ Lugo } & \multicolumn{3}{|c|}{ Ourense } & \multicolumn{3}{|c|}{ Pontevedra } \\
\hline & & Votos & $\%$ & Escaños & Votos & $\%$ & Escaños & Votos & $\%$ & Escaños & Votos & $\%$ & Escaños \\
\hline \multirow[t]{3}{*}{ Censo } & Sin emigrantes & 941.495 & & & 312.683 & & & 290.092 & & & 753.777 & & \\
\hline & Emigrantes & 92.271 & & & 32.564 & & & 59.734 & & & 68.416 & & \\
\hline & Con emigrantes & 1.003 .766 & & & 345.247 & & & 350.636 & & & 822.193 & & \\
\hline \multicolumn{2}{|c|}{ Votantes } & 614.019 & $59^{\prime} 1$ & & 223.050 & $644^{\prime}$ & & 212.292 & & $60 ' 5$ & 495.326 & 596 & \\
\hline \multicolumn{2}{|l|}{$\mathrm{PP}$} & 296.734 & 487 & 12 & 124.042 & 56 & 9 & 121.073 & $57 \%$ & 8 & 250.036 & $50^{\prime} 8$ & 12 \\
\hline \multicolumn{2}{|l|}{ BNG } & 146.816 & $24^{\prime} 1$ & 6 & 43.245 & $19^{\prime} 5$ & 3 & 42.780 & $20 ' 3$ & 3 & 113.582 & $23^{\prime} 1$ & 5 \\
\hline \multicolumn{2}{|l|}{ PSOE } & 139.662 & 229 & 6 & 47.838 & $21^{\prime} 6$ & 3 & 40.695 & $19^{\prime} 3$ & 3 & 106.624 & $21^{\prime} 7$ & 5 \\
\hline \multicolumn{2}{|l|}{ Otros } & 15.175 & 25 & & 3.568 & 16 & & 4.036 & 19 & & 12.031 & 23 & \\
\hline
\end{tabular}




\section{ANÁLISIS DE LOS RESULTADOS}

En primer lugar, habría que delimitar la analítica en función de las diferencias existentes entre el voto emitido en el territorio de la Comunidad Autónoma y el voto emigrante. Este último, como es sabido, estuvo teñido de irregularidades relacionadas con el censo antes de la campaña y era considerado por todas las fuerzas políticas como un posible "colchón" de sufragios en el hipotético supuesto de que el Partido Popular no hubiese alcanzado la mayoría absoluta con el voto residente, como muestra la abrumadora diferencia a su favor. Finalmente, no resultó necesario ni tampoco varió los resultados como sí había sucedido en las elecciones autonómicas de $1997^{6}$. De todas formas, no parece cohonestable con la limpieza de unos comicios la evidencia de que el censo emigrante se encuentre plagado de errores. ¿Qué hubiese acontecido si el voto de los ausentes hubiera determinado una decisión final distinta a la de los residentes en el territorio? Quizás habría que pensar en soluciones de otra índole, sugeridas en numerosas ocasiones para el Parlamento de Galicia y aplicadas en otros países como Portugal, tales como la posibilidad de crear una circunscripción propia para la emigración, aunque seguiría siendo una elección en dos fases, un tanto tercermundista. Obsérvese, además, la tremenda paradoja de que los emigrantes votantes no computan a la hora de determinar el reparto de escaños entre circunscripciones: Ourense, con emigrantes, tiene 5.000 votantes más que Lugo $\mathrm{y}$, sin embargo, elige un escaño menos.

Dejando de lado la abstención de este voto emigrante, elocuente por sí misma, convendría señalar que, de nuevo, ha experimentado un incremento en el territorio gallego que la sitúa levemente por encima de la fuerza política más votada, aunque dentro de cotas que nuestro sistema político y sus actores protagonistas admiten, implícita y explicitamente, como dentro de la normalidad, sin que merezca mayores consideraciones, cuando lo cierto es que debiera resultar preocupante. A este dato habría que añadirle el notorio aumento de la cifra de votos en blanco (más de 25.000) y nulos (unos 10.000), de los cuales 17.265 y 4.908 , respectivamente, le correspondian a las siete ciudades gallegas y sus áreas metropolitanas que reúnen la mitad del censo electoral; los votos en blanco se han situado en cuarto lugar, tras los tres partidos que obtienen representación y por encima de todos los demás (Izquierda Unida sobrepasa ligeramente los 10.000 votos). También, en

6 Aunque por el estrecho margen de 700 votos en la provincia de Ourense, que le hubieran restado el tercer escaño al PSOE en esta circunscripción. 
general, la abstención gana adeptos en las zonas más urbanas, superando en seis de las siete ciudades referidas las respectivas medias provinciales, y resultando más participativas (con la notoria diferencia de seis puntos porcentuales) las dos provincias más rurales, despobladas y sobrerrepresentadas en el Parlamento autonómico, Lugo y Ourense, justamente aquellas en las que el Partido Popular obtiene mayores distancias con sus contrincantes 7 .

En relación con el triángulo político gallego, parece mantenerse incólume en sus tres lados, ya que el Partido Popular conserva su cómoda mayoría absoluta, perdiendo un solo escaño desde 1997 (pasa de 42 a 41) y menos de un punto en porcentaje de voto, siguiendo por encima del $50 \%$ en la media gallega, no superándola en la provincia de A Coruña, pero acercándose al $60 \%$ en la de Ourense y algo menos en Lugo. No alcanza los espectaculares resultados de las autonómicas de 1993 y 1997 ni de las generales del 2000, pero continúa permeando los distintos segmentos electorales de Galicia; es un valor seguro que sólo deja margen de duda sobre si reproducirá o no mayoría absoluta y en que cuantía se cifrará ésta. Las incógnitas sobre la sucesión las administrará el propio Fraga y, para quien esto escribe, no parece que el futuro candidato, si consigue mantener el partido unido y no es impuesto unilateralmente por el aparato central de Madrid, vaya a derrochar un capital político sumamente bien administrado, única expectativa en la que se ha basado una desmotivada oposición en los últimos años. Si en algún aspecto se puede hablar de relativa flaqueza electoral es en el voto urbano; por supuesto es la fuerza más votada en las siete ciudades gallegas, pero únicamente en Santiago de Compostela ha sobrepasado el 21 de octubre el $50 \%$ de los sufragios, y es esta una urbe con un voto dual manifestado elección tras elección, ya que en las locales vence de forma casi sistemática el conjunto de la izquierda. Aunque tampoco cabe extrapolar resultados en las restantes ciudades, sí que se percibe un leve incremento del eje BNG-PSOE e incluso se ha acentuado rondando entre ambos el $50 \%$ del voto de las siete ciudades por el $44 \%$ del PP, lo que provoca que en el conjunto del voto urbano el respaldo censal al PP es del $27 \%$ por un $43 \%$ en el censo rural. Es decir, se patentiza una cierta polarización en el apoyo social

7 Esta sobrerrepresentación resulta notable en detrimento de Pontevedra y A Coruña. Lugo, con menos de un tercio de votantes que A Coruña elige 15 escaños frente a 24 . Ourense, con poco más de un tercio de votantes que Pontevedra, ocupa 14 escaños frente a 22 de ésta última. Sin computar el censo emigrante, una cuarta parte de los votantes gallegos eligen cerca del $40 \%$ de los escaños de su Cámara representativa. 
del Partido Popular que quiebra livianamente la hegemonía que antes tenía en todos los estratos de la sociedad gallega.

En el ámbito del nacionalismo gallego del BNG, se ha frenado una marea ascendente que parecía imparable y con movimiento propio $o$, al menos, eso es lo que habían creído sus dirigentes, descendiendo un escaño (de 18 a 17) y más de dos puntos porcentuales (tal resultado incluso provocó el error del CIS quien le atribuía una horquilla mínima de 18 escaños). Resulta obvio que no se puede afirmar que el Bloque alcanzó su techo en 1997, como así se apresuraron a hacerlo los medios de comunicación regionales, pero también es verdad que esta fuerza ha entrado en un período de catarsis que podría durar hasta las próximas elecciones locales, sin que se atreva antes a cambiar de liderazgo o a reformar su peculiar modelo organizativo interno, un tanto esclerotizado y con un aparato envejecido ${ }^{8}$. El dilema estribará en el mantenimiento de las rigideces mencionadas, arriesgándose a perder lo costosamente ganado ${ }^{9}$, o en efectuar una apuesta de ampliación del espectro social a costa, sobre todo, de dejar atrás ciertos elementos de izquierda real, resistencialistas y obviamente perjudiciales en la arena electoral; en el cleavage del nacionalismo-galleguismo resulta evidente que no se ha avanzado posicionalmente tanto como la propia sociedad gallega que ya no es aquélla a la que se dirigían los nacionalistas de la Segunda República (labriegos y marineros), y aún queda un importante bagaje para la apuesta política en este ámbito, siempre que la ideología y el discurso conecten con el sector de la ciudadanía más políticamente activo y no sólo se suavicen para mejor venderlos en el mercado electoral.

EI PSOE se encuentra atenazado por tantos dilemas que sería imposible resumirlos en estas páginas. Han firmado un pacto con los nacionalistas en los gobiernos locales ${ }^{10}$ y su principal Alcalde es un furibundo antinacionalista. Ante el hipotético dilema de dejar gobernar la Xunta a un Partido Popular en minoría en el Parlamento o entregarle la Presidencia de la misma a Xosé Manuel Beiras, nunca llegó a

8 Pocos jóvenes y pocas mujeres en una fuerza política votada por electores jóvenes y de izquierdas, son elementos que hacen aflorar por sí solos las contradicciones del Bloque.

9 Es evidente que parte del electorado fluctúa entre el PSOE y el BNG, alternando fácilmente su voto entre ambas fuerzas en función de las circunstancias o el tipo de elección.

10 Los cuales no han resultado especialmente fluidos en la relación, sobre todo por parte del PSOE en los Ayuntamientos en los que ocupa el lugar secundario, lo que, en buena medida, suponía un mensaje para el electorado de lo que podría acontecer en el nivel autonómico. 
existir definición oficial y parecieron aliviados de no tener que tomar una decisión, es decir, fueron felices con la victoria por mayoría absoluta de Fraga. Unas ambiciones políticas sustentadas en la aspiración de llegar a ser segunda fuerza política a gran distancia de la primera, parecen pensar poco en clave gallega y más en estatal, ya que el incremento de dos diputados (de 15 a 17) y dos puntos porcentuales no ha impedido que sigan siendo tercera fuerza política en Galicia, aunque en situación de empate técnico. Es cierto que el actual candidato, Emilio Pérez Touriño, logró poner fin a doce años de caída libre en comicios autonómicos de su partido, pero no lo es menos que el trasvase de sufragios que se puede producir entre BNG y PSOE o viceversa, no resulta suficiente para generar una alternativa política creíble en la Comunidad Autónoma, lo cual es lo mismo que decir que al partido mayoritario le basta con depender de los errores de sus competidores más que de sus propios aciertos para sostenerse como hasta ahora, ya que entre aquéllos mantienen un juego de suma cero destinado a perpetuarlos en la oposición. 